\title{
Distribución geográfica del riesgo de rabia de origen silvestre y evaluación de los factores asociados con su incidencia en Colombia, 1982-2010
}

\author{
Diana Marcela Brito-Hoyos, ${ }^{1}$ Edilberto Brito Sierra ${ }^{2}$ \\ y Rafael Villalobos Álvarez ${ }^{2}$
}

Forma de citar

Brito-Hoyos DM, Brito Sierra E, Villalobos Álvarez R. Distribución geográfica del riesgo de rabia de origen silvestre y evaluación de los factores asociados con su incidencia en Colombia, 1982-2010. Rev Panam Salud Publica. 2013;33(1):8-14.

RESUMEN Objetivo. Actualizar la información sobre la distribución geográfica de los focos de rabia transmitida por quirópteros en Colombia y evaluar las condiciones bióticas y abióticas asociadas con la incidencia de esta enfermedad en el país.

Métodos. Estudio observacional a partir de una base de datos construida con la información de los focos de rabia silvestre detectados entre 1982 y 2010 y la población bovina de cada municipio. Se clasificaron los municipios según el riesgo de transmisión de la enfermedad y se realizó una caracterización ambiental de 15 variables. Se elaboró un modelo de máxima entropía para predecir las zonas con condiciones apropiadas para la presencia del vector Desmodus rotundus infectado por el virus y evaluar la importancia de las variables empleadas.

Resultados. Se presentaron 2330 focos en 359 (31,8\%) de los 1128 municipios del país; 144 municipios se clasificaron como de alto riesgo. Montería, Valledupar, Riohacha, Aguachica, Unguía, Acandi, Río de Oro, Tibú, Sahagún y San Onofre concentraron las mayores tasas de incidencia. Los focos de rabia se presentaron a lo largo de todo el año, aunque en los meses secos (de enero a abril) se observó una mayor frecuencia (correlación lineal [r] = 0,64). La temperatura y las precipitaciones son las variables que más robustez aportaron al modelo de predicción.

Conclusiones. Se recomienda aplicar medidas de control y prevención en los municipios con alto riesgo. Los mejores meses para realizar jornadas de vacunación son junio, noviembre y diciembre. En futuros análisis se deben incluir variables de interacción biótica para mejorar la capacidad predictiva del modelo.

Palabras clave Rabia; vectores de enfermedades; factores epidemiológicos; localización geográfica de riesgo; Colombia.

La rabia es una zoonosis viral que afecta al sistema nervioso central de los

Pontificia Universidad Javeriana, Bogotá, Colombia. La correspondencia se debe dirigir a Diana Marcela Brito-Hoyos, d.brito@javeriana.edu.co

2 Instituto Colombiano Agropecuario, Bogotá, Colombia. mamíferos y causa la muerte de la mayoría de los afectados (1). Se estima que 70000 personas mueren anualmente por esta enfermedad en el mundo (1) y, aunque afecta a todos los grupos de edad, su incidencia es de 3 a 5 veces más elevada en los menores de 15 años (2).
Desde el punto de vista epidemiológico, la enfermedad puede desarrollarse en un entorno urbano, donde los perros son su principal vector, o silvestre, en el que los murciélagos hematófagos son los reservorios y transmisores fundamentales (1). 
La rabia transmitida por murciélagos es un importante problema de salud pública en áreas tropicales y subtropicales de América (3) y afecta a la ganadería por causar la parálisis y la muerte de bovinos (3). Como los murciélagos muerden a sus presas mientras duermen y su mordedura es casi indolora e indetectable (4), en algunos casos el diagnóstico de la enfermedad se realiza post mórtem (5). A la fecha, los sobrevivientes al virus de la rabia son personas que recibieron el tratamiento oportuno antes o inmediatamente después de la mordedura de un animal infectado (1).

La exposición de las personas al virus en el ámbito rural depende de la combinación de varios factores, tanto biológicos - presencia de Desmodus rotundus, existencia de lugares y alimentos que permitan su subsistencia, y la circulación del virus (6)-, como de otro tipo - condiciones socioeconómicas y actividad productiva predominantes en la zona, expansión de la población a áreas rurales, posibilidades de acceso oportuno a medicamentos profilácticos o al tratamiento-, además de la aplicación o no de medidas para controlar las poblaciones de murciélagos hematófagos (6).

En 2005, la Organización Mundial de la Salud (OMS) informó que el número de casos de rabia humana de origen silvestre en América Latina fue mayor que el de casos de rabia urbana (7). En la Región de las Américas, según la Organización Panamericana de la Salud (OPS), los casos de rabia urbana se redujeron en $90 \%$ en los últimos 20 años, mientras que los casos de rabia silvestre aumentaron considerablemente (8).

El Instituto Colombiano Agropecuario (ICA) informó en 2005 que a medida que disminuye la rabia urbana toma mayor importancia la de origen silvestre, e identificó a $D$. rotundus como su principal transmisor en el país (9). Esto es congruente con la situación epidemiológica de América Latina y confirma la necesidad de prestar atención permanente e integral al problema, tanto con respecto a la diseminación del virus como del vector.

El ICA identificó las zonas con riesgo de transmisión de rabia silvestre en Colombia a partir del análisis de los focos detectados entre 1982 y 2002 (9), lo que permitió reajustar las acciones del programa nacional de control del virus. El conocimiento desactualizado de los municipios que presentan mayores riesgos de rabia hace que las medidas sanitarias de prevención y control sean ineficaces e ineficientes en estos momentos.

En consecuencia, el objetivo de esta investigación fue actualizar la información sobre la distribución geográfica de los focos de rabia transmitida por quirópteros en Colombia y evaluar las condiciones bióticas y abióticas asociadas con la incidencia de esta enfermedad en el país.

\section{MATERIALES Y MÉTODOS}

\section{Base de datos}

Para este estudio observacional se construyó una base de datos con la información de los focos de rabia silvestre detectados entre 1982 y 2010 (fecha, departamento, municipio, predio, variante antigénica, latitud y longitud) a partir de la información proporcionada por las direcciones de diagnóstico y epidemiología veterinaria del ICA.

De todos los focos notificados, solo se utilizaron los diagnosticados mediante inmunofluorescencia indirecta con anticuerpos monoclonales como variantes antigénicas 3 y 5, por ser las transmitidas por vectores quirópteros.

Una vez depurada la base de datos, se trabajó con 234 focos referenciados mediante el sistema de coordenadas decimales y 2096 focos que identificaban su ubicación geográfica mediante los cuadrantes epidemiológicos diseñados por el Centro Panamericano de Fiebre Aftosa, de la OPS. Para transformar la ubicación de estos últimos a coordenadas decimales aproximadas, se siguió la metodología propuesta por el ICA (9) mediante el programa informático ArcGIS versión 9.2, que permite superponer un mapa con la división política de todos los municipios de Colombia sobre un mapa de cuadrantes y subcuadrantes.

De esta forma se construyó un mapa vector de puntos con la ubicación de los 2330 focos de interés.

\section{Análisis estadístico y corredor endémico}

La base de datos se ordenó por fecha de inicio de los focos y se obtuvieron los estadísticos descriptivos y los valores intercuartiles de la incidencia de rabia ocurrida en cada uno de los municipios del país, mediante tablas dinámicas, con el paquete informático SPSS versión 19.

A partir de los registros mensuales de los últimos siete años del estudio
(2004-2010) y sus medias aritméticas se construyeron corredores endémicos (10), y con el fin de conocer las fluctuaciones de frecuencia de la enfermedad y establecer su estado epidemiológico en el país se obtuvieron los gráficos de áreas que reflejan la actividad del virus (11).

\section{Clasificación del riesgo por municipio}

No se tuvo en cuenta la distribución del murciélago en Colombia como variable biótica del modelo, al no ser una li-mitante para la distribución del virus; D. rotundus tiene una amplia distribución que va desde el norte de México hasta el norte de Argentina y Chile, y desde el nivel del mar hasta $3500 \mathrm{~m}$ de altura (12).

Así, como variable biótica se tomó la población bovina por municipio, ya que en los departamentos ganaderos se ha registrado una mayor incidencia de personas afectadas por la rabia (13); se considera que cada vaca infectada equivale en promedio a la exposición de 20 personas (13). La información de la población bovina se obtuvo a partir del Censo Nacional Pecuario de 2010.

Se dividió el número de focos entre la población bovina de cada municipio para obtener la clasificación de riesgo según las categorías de la Oficina Internacional de Epizootias (14). Los municipios con una incidencia absoluta de focos por debajo del percentil 25 se clasificaron como de riesgo insignificante; los que presentaron una incidencia entre el percentil 25 y el 50 se clasificaron como de riesgo bajo; como de riesgo medio, los que quedaron entre el percentil $51 \mathrm{y}$ el 75; y los que tenían una incidencia mayor del percentil 75 se clasificaron como municipios de alto riesgo.

Una vez obtenida la clasificación de los municipios, se construyó el mapa de riesgo mediante el programa informático ArcGis versión 9.2.

\section{Variables abióticas}

Se seleccionaron 15 variables que podrían afectar a la fisiología del vector y limitar su establecimiento en diferentes áreas: altitud, temperatura media anual, estacionalidad de la temperatura, espectro anual de temperaturas, temperatura media del trimestre más húmedo, temperatura media del trimestre más seco, temperatura media del trimestre más cálido, temperatura media del trimestre más frio, volumen de precipitación 
anual, estacionalidad de la precipitación, precipitación del trimestre más húmedo, precipitación del trimestre más seco, precipitación del trimestre más cálido, precipitación del trimestre más frio, y orientación y porcentaje de la pendiente. Las variables abióticas se referenciaron mediante capas de información ambiental ${ }^{3}$ con una resolución de 1 píxel por $\mathrm{km}^{2}$.

\section{Modelo de máxima entropía}

Para modelar los sitios con condiciones apropiadas para la presencia de D. rotundus con rabia y evaluar la importancia de las variables caracterizadas, se combinaron los 2330 registros espaciales y las capas de información ambiental mediante el programa MaxEnt versión 3.3.3, basado en el modelo de máxima entropía (15). De esta forma se pudo establecer el nicho ecológico potencial del vector infectado por el virus, que refleja la probabilidad estimada de encontrar las condiciones apropiadas para que se establezca la especie en un área geográfica determinada (15).

La mitad de los 2330 registros, seleccionados aleatoriamente, se empleó para obtener el modelo, mientras el resto se utilizó para realizar una prueba de ajuste del modelo con 5000 iteraciones.

\section{RESULTADOS}

\section{Situación epidemiológica}

La distribución geográfica de los focos de rabia de origen silvestre en el territorio colombiano no es homogénea: pocos municipios del país presentan conglomerados, mientras la mayoría del territorio se encuentra libre de focos (figura 1).

Los focos de rabia estuvieron presentes en 31 departamentos de Colombia; el Archipiélago de San Andrés fue el único totalmente libre de esta enfermedad.

En ocho departamentos se notificaron 1595 (68,5\%) de los focos registrados en el país; estos fueron: César (388 focos), Córdoba (355 focos), Antioquia (182 focos), Chocó (147 focos), La Guajira (135 focos), Arauca (132 focos), Santander (129 focos) y Casanare (127 focos). Por consiguiente, estos son los departamentos con mayor riesgo de transmisión de rabia. Los departamentos con menos focos fueron Vaupés, Guainía y Amazonas, con 1,2 y 3 focos, respectivamente. Estos

3 Ver en http://www.worldclim.org

FIGURA 1. Ubicación geográfica de los focos de rabia transmitida por quirópteros en Colombia durante el período 1982-2010

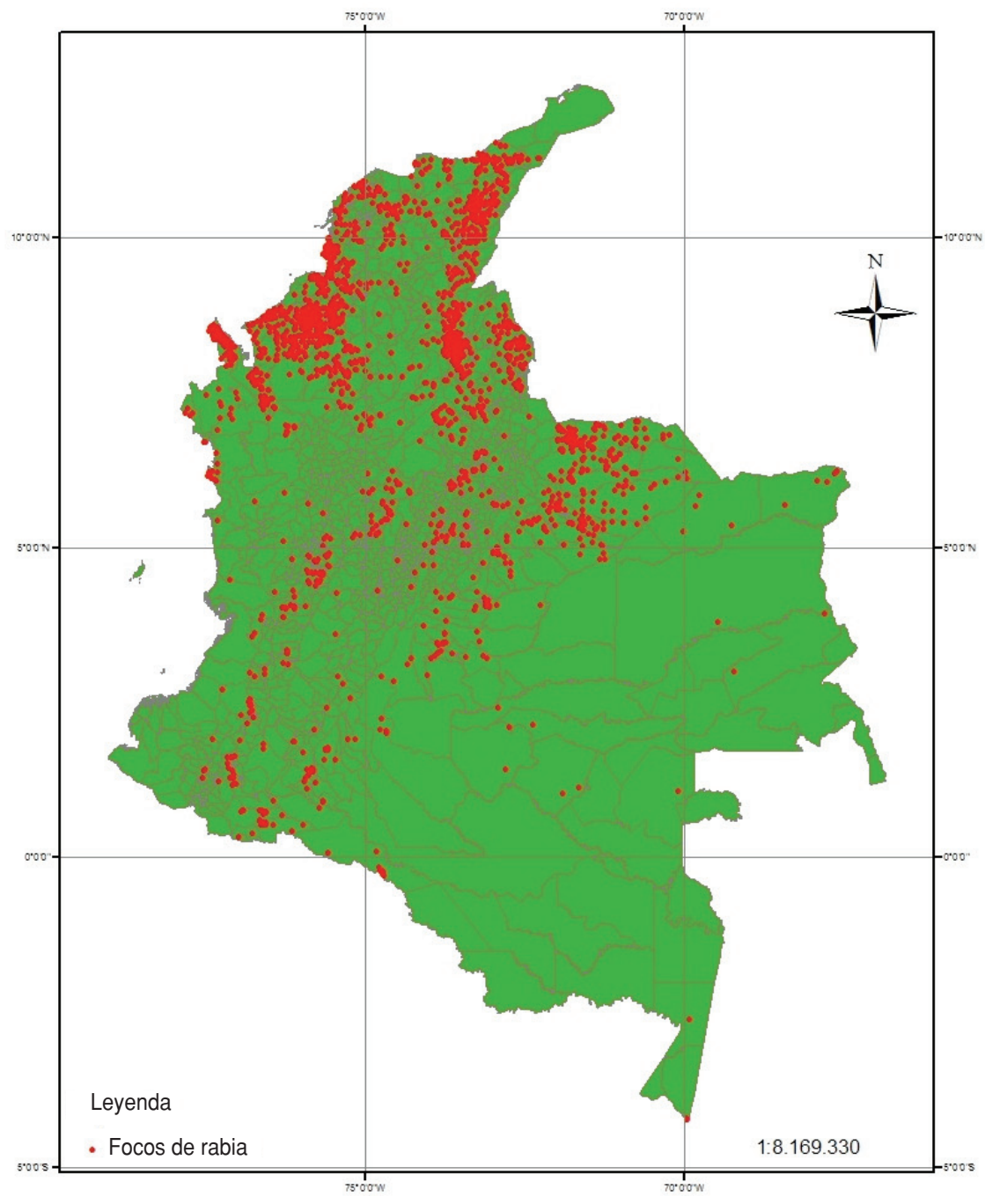

departamentos son también los que tienen la menor población bovina en el país.

Los cambios en la incidencia anual no siguen un comportamiento que indique la ocurrencia de ciclos (figura 2). Entre los años 1995 y 2001 se observó una reducción en el número de focos, que puede deberse a una reducción natural de la transmisión, a problemas de notificación o ser el resultado de acciones de control llevadas a cabo por el ICA. En contraste, a partir de 2002 se vio una clara tendencia ascendente del número de focos, con un máximo en el año 2010 (figura 2). Se requieren estudios adicionales para explicar este comportamiento.

Los focos de rabia se presentaron a lo largo de todo el año, aunque en los meses secos (de enero a abril) se observó una mayor frecuencia (correlación lineal $[r]=0,64)$.
En el corredor endémico se observaron fluctuaciones en el número de focos en el año 2011 (figura 3).

\section{Clasificación del riesgo por municipio}

Se presentaron focos positivos en 359 (31,8\%) de los 1128 municipios del país; el municipio con mayor incidencia fue Montería (departamento de Córdoba), con 105 focos, seguido de Valledupar (César), Riohacha (La Guajira), Aguachica (César), Unguía (Chocó), Acandí (Chocó), Río de Oro (César), Tibú (Norte de Santander), Sahagún (Córdoba) y San Onofre (Sucre), todos en el norte del país.

Según los niveles intercuartiles, establecidos a partir de la incidencia encontrada en los municipios (entre 1 y 105 focos), los municipios que presentaron 
FIGURA 2. Número de casos positivos anuales de rabia transmitida por quirópteros, Colombia, 1982-2010

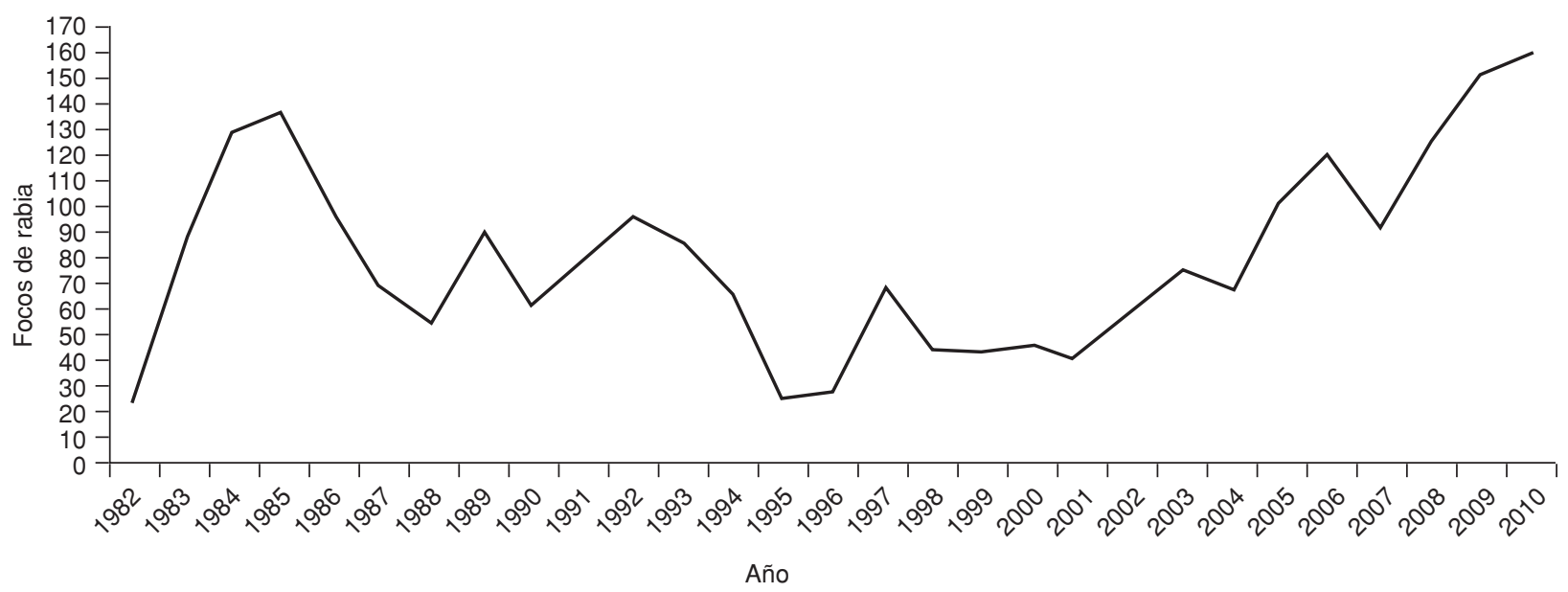

FIGURA 3. Fluctuación normal de la incidencia para cada mes del año, según el análisis de corredor endémico de la rabia transmitida por quirópteros en Colombia, 2011

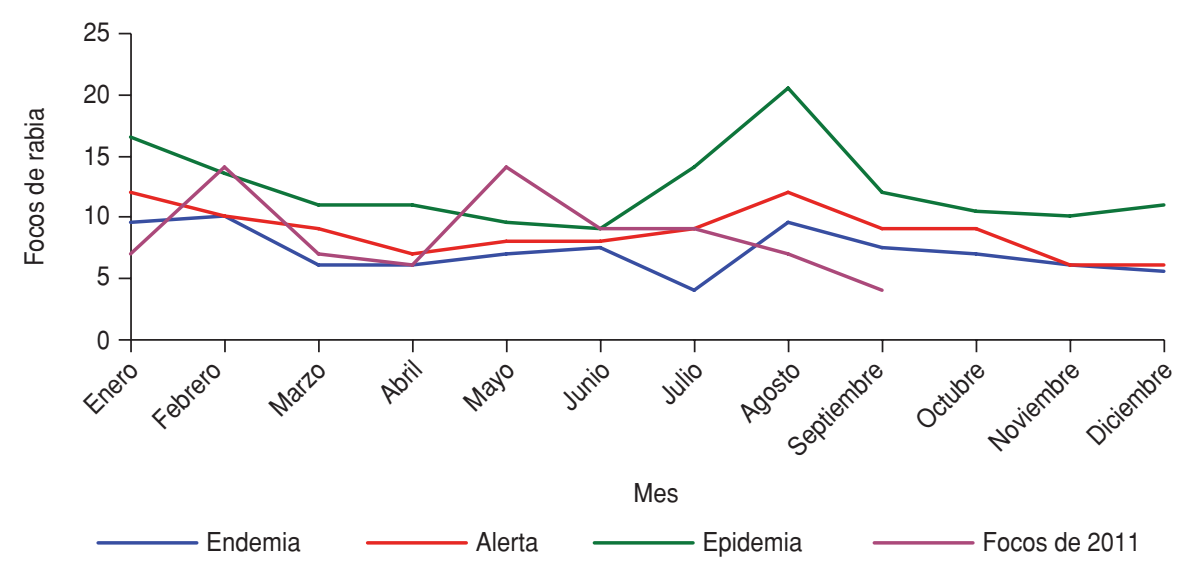

1 foco de rabia en el período estudiado se clasificaron como de riesgo insignificante (primer cuartil); los que presentaron 2 focos, como de riesgo bajo (segundo cuartil); los que presentaron de 3 a 7 casos, como de riesgo medio (tercer cuartil); y los municipios con 8 focos o más, como de riesgo alto (figura 4). En total, 144 municipios alcanzaron la categoría de riesgo alto.

\section{Modelo de máxima entropía}

La probabilidad estimada de encontrar las condiciones apropiadas para la especie $D$. rotundus en un área geográfica determinada varió entre 0 y 1 (figura 5). Las zonas con mayor probabilidad de presentar condiciones favorables para la transmisión de la rabia en Colombia se concentran en las regiones del Caribe y del Pacífico, seguidas de las zonas ubicadas a lo largo de las tres cordilleras colombianas.

El ajuste del modelo fue de 0,855 , lo que indica que tuvo una buena sensibilidad y un elevado poder de predictibilidad (16); las precipitaciones del trimestre más seco del año es la variable individual que mejor predijo la distribución de la enfermedad en el reservorio. Otras variables, como las precipitaciones anuales, las temperaturas medias de los trimestres más húmedo y más frio del año y la estacionalidad de las precipitaciones, elevaron el poder de predictibilidad del modelo y son factores limitantes de la distribución de la enfermedad.

\section{DISCUSIÓN}

Los cambios en la incidencia del virus a lo largo del período de estudio (figura 2) pueden ser explicados por las varia- ciones climáticas anuales que afectan al vector. En los meses de lluvia, por ejemplo, hay un menor número de focos que en los meses de seca, debido a que los murciélagos reducen su actividad cuando determinadas condiciones climáticas, como la lluvia, obstaculizan su vuelo (17). Esto explicaría la disminución de la transmisión de la enfermedad y, consecuentemente, del número de focos notificados. Sin embargo, es particularmente notable la disminución del número de registros en 1999, año en el que Colombia se encontraba bajo la fuerte influencia del fenómeno climatológico El Niño, que provocó una fuerte sequía (18).

Existe un problema de escala en los cambios estacionales de los registros. Por la ubicación geográfica de Colombia y sus características fisiográficas, el clima del país es muy variado, tanto a lo largo de su territorio como en el transcurso del año (18). Así, mientras algunas zonas del país - como las regiones andina y caribeña- presentan dos picos de lluvias al año, otras - como las regiones ubicadas en las cuencas del Orinoco y el Amazonas- presentan un solo pico. Por su parte, la región aledaña a la costa del Océano Pacífico, donde se encontró un gran número de focos de rabia, no tiene un perfil definido de lluvias, con diferencias mensuales mínimas (18). Esto resalta la importancia de llevar el análisis a una escala espacial mayor, en el que el área de estudio sea más pequeña y las condiciones más homogéneas.

Los resultados de este estudio demuestran la utilidad de combinar los registros históricos de ocurrencia de focos de rabia de origen silvestre con los 
FIGURA 4. Clasificación de los municipios según el riesgo de ocurrencia de rabia transmitida por quirópteros, normalizada por la población bovina, Colombia, 1982-2010

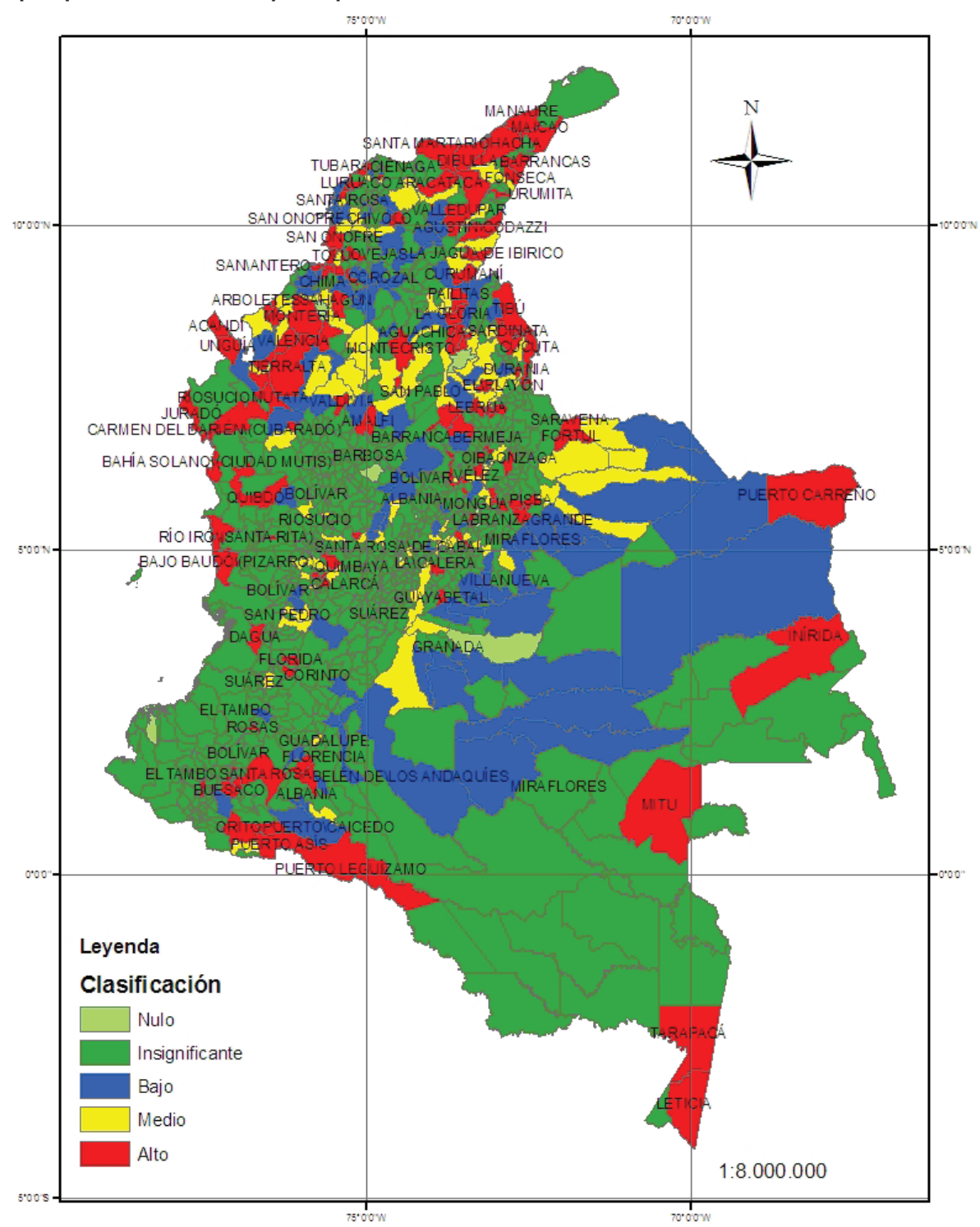

datos de las variables bióticas y abióticas relacionadas con la transmisión de esta enfermedad (figura 5). Los modelos de nicho ecológico constituyen una herramienta útil para estudios ecológicos, epidemiológicos y de conservación (19), ya que, incluso con pocos registros de la circulación del virus o de la presencia del vector, se puede predecir con suficiente precisión la distribución geográfica de la enfermedad y las posibilidades de su expansión a diferentes zonas (20). Además, se puede establecer mediante mapas el efecto de diferentes variables climáticas sobre la distribución de la enfermedad (21), especialmente en zonas de geografía muy variable, como ocurre en Colombia, donde se requiere de una resolución espacial elevada.
Las variables ambientales obtenidas de Worldclim resultaron adecuadas para la realización de este análisis (22), al igual que el modelo de máxima entropía generado por el programa informático MaxEnt, que permitió estimar la distribución de la enfermedad en los municipios con alto riesgo (figura 4). El empleo de registros históricos como los utilizados aquí — que abarcan los registros de focos en un período de 29 años y los datos ambientales promedios anuales de los últimos 50 años (22) — aumenta la robustez de las predicciones de este modelo (23).

Existen datos científicos que demuestran que los procesos ecológicos e históricos desempeñan un papel determinante en la estructura de la comunidad y afectan a escala local y general a la distribución de las diferentes especies (24); sin embargo, aún no se ha probado la influencia de este tipo de variables para la comunidad de murciélagos hematófagos $D$. rotundus en Colombia, vector y reservorio del virus de la rabia, debido a la falta de series históricas nacionales de este tipo de variables.

Aunque en el presente estudio el modelo se elaboró solamente con datos de los focos de rabia notificados, se alcanzó una elevada sensibilidad $(0,855)$, lo que respalda la solidez de los datos y la predicción (16). Si bien se ha discutido acerca de las ventajas y desventajas de las predicciones a partir de este tipo de información, los modelos basados en datos de presencia y de presenciaausencia permiten llegar a predicciones con un buen nivel de certeza a una escala adecuada, cuando se cuenta con datos suficientes y precisos de la especie estudiada (25). Además, se requiere de información de otras variables de relevancia ecológica para la especie, como las perturbaciones locales que provocan la perdida y la degradación del hábitat y las interacciones bióticas con otras especies (24).

El ajuste del modelo obtenido indica que los valores de las predicciones generadas explican la distribución del riesgo mejor que el azar, y que el error del modelo es aceptable (26). Es importante tener en cuenta que como $D$. rotundus es una especie con una distribución amplia, el ajuste presenta valores intermedios; los modelos de nicho como este son más precisos para especies microendémicas con áreas de distribución más restringidas (26).

El modelo permitió establecer que las variables precipitación y temperatura son determinantes para predecir la distribución de la rabia transmitida por D. rotundus en Colombia; estas variables influyen en el entorno térmico de los murciélagos, que tienen dificultades para regular la temperatura (27). Si bien para hacer frente a las bajas temperaturas, los murciélagos aumentan sus movimientos a fin de acelerar su metabolismo (28), el vuelo aumenta las tasas de pérdida de agua por evaporación (29), por lo que esta no es una opción viable para las especies hematófagas. Aunque D. rotundus es capaz de regular su temperatura, debe compensar el costo energético que implica establecerse en lugares con niveles de precipitación y temperaturas menos favorables para su fisiología. 
FIGURA 5. Representación del modelo MaxEnt para Desmodus rotundus infectado por el virus de la rabia

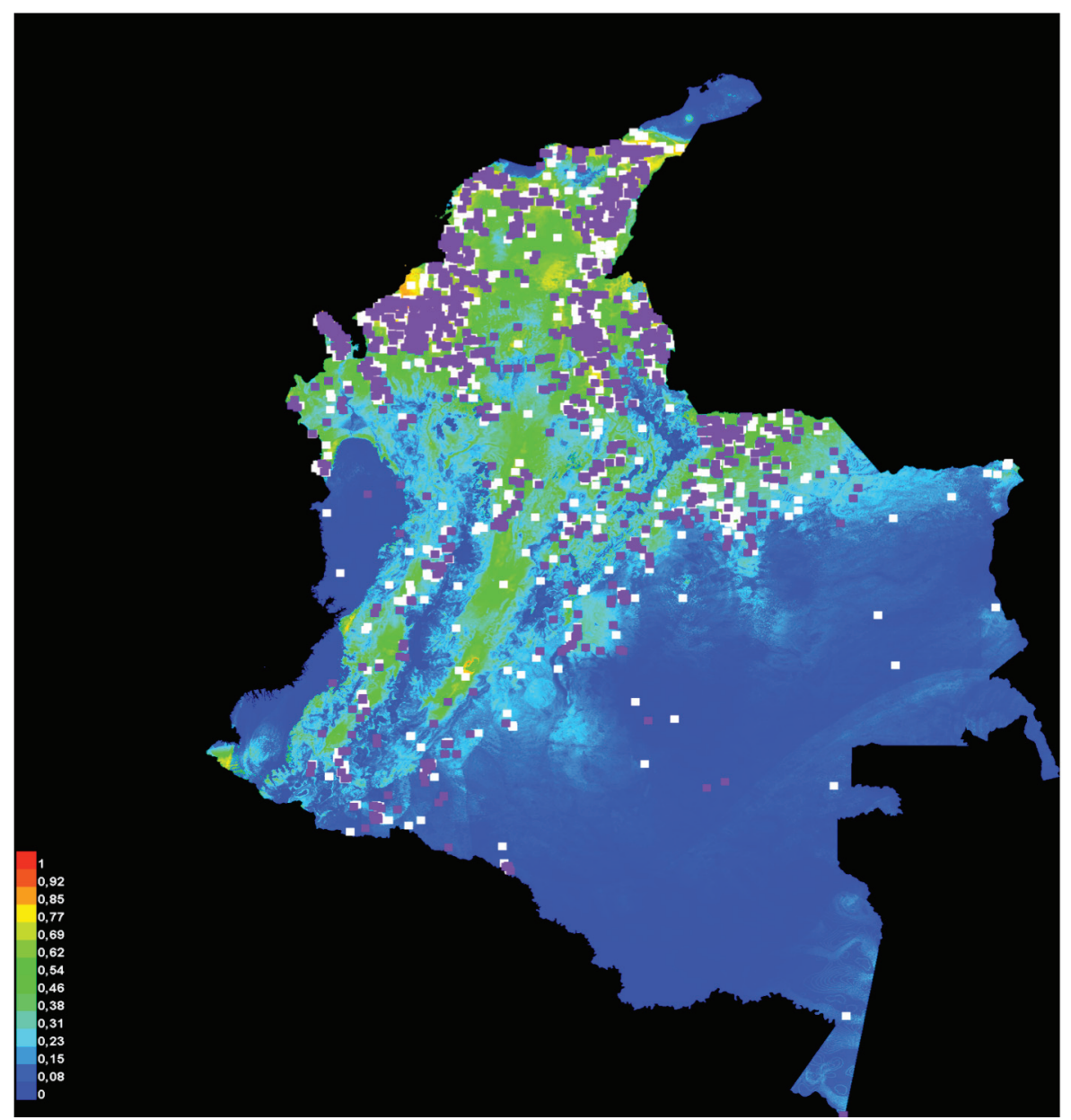

Leyenda: Los puntos blancos muestran la ubicación de los focos de entrenamiento, mientras que los puntos violetas indican los puntos de prueba del modelo. El color rojo señala las áreas con alta probabilidad de encontrar condiciones favorables para la especie, el verde señala las zonas con condiciones típicas de lugares donde se ha encontrado la especie y el color azul claro indica una baja probabilidad de que las condiciones del lugar sean favorables para la especie (16).

$\mathrm{Al}$ analizar estos resultados se deben tener en cuenta algunas limitaciones. En primer lugar, se debe considerar el sesgo que puede introducir el hecho de que los datos proporcionados por el ICA se restringen a las zonas de Colombia donde la cobertura de su red institucional es mejor, lo que deja extensas zonas sin posibilidades de notificar todos los casos. Además, existen solamente nueve laboratorios que hacen diagnóstico de rabia en Colombia (13), por lo que la capacidad de procesamiento de muestras es reducida y pueden perderse casos en las zonas que no están atendidas por esos laboratorios (30).

Finalmente, hay variables que no se consideraron en el modelo de máxima entropía debido a la poca información disponible y a la escala del estudio. Algunas de estas variables, como las interacciones bióticas y las barreras geográficas e his- tóricas, podrían explicar por qué algunas especies no ocupan todas las áreas con ambientes favorables. La incorporación de estas variables al modelo podría contribuir a generar predicciones más robustas en lugares donde la información es limitada o nula, como el caso de la región amazónica.

A pesar de estas limitaciones, la modelación del nicho ecológico y la información generada a partir de 2330 registros de rabia transmitida por quirópteros, recolectados durante 29 años, permitieron establecer con un apropiado nivel de certeza el riesgo de transmisión del virus en los municipios de Colombia. Se recomienda la aplicación de medidas sanitarias de control de la enfermedad en los municipios que presentaron el mayor número de focos (Montería, Valledupar, Riohacha, Aguachica, Unguía, Acandí, Río de Oro, Tibú, Sahagún y San Onofre), con el fin de reducir la transmisión a especies silvestres, el ganado e, incluso, a las personas.

Las altas temperaturas y los bajos niveles de precipitación favorecen la presencia de $D$. rotundus que, al estar infectados por el virus de la rabia, aumenta la probabilidad de transmisión al ganado y, en consecuencia, a la población del lugar.

Los mejores meses para realizar las jornadas de vacunación en bovinos y otras especies domesticas son junio, noviembre y diciembre, cuando la enfermedad se encuentra en su pico más bajo. La vacunación de los posibles hospederos contribuiría a reducir el número de casos de rabia.

En futuros análisis espaciales, se recomienda utilizar una escala local que permita conocer más profundamente las interacciones bióticas, lo que elevaría la confiabilidad de la predicción.

Agradecimientos. Se agradece al Instituto Colombiano Agropecuario y a la Pontificia Universidad Javeriana por facilitar el análisis de los datos.

Conflicto de intereses. Ninguno declarado por los autores.

\section{REFERENCIAS}

1. Adedeji AO, Okonko OI, Eyarefe O, Adedeji $\mathrm{OB}$, Babalola ET, Ojezele MO, et al. An overview of rabies - history, epidemiology, control, and possible elimination. African J Microbiol Res. 2010;4:2327-38.

2. Bourhy H, Dautry-Varsat A, Hotez PJ, Salomón J. Rabies, still neglected after 125 years of vaccination. PLoS Negl Trop Dis. 2010;4(11):e389.

3. World Health Organization. Expert consutation on rabies. First report. Geneva: WHO; 2005.

4. Wilkerson JA. Rabies update. Wilderness Environ Med. 2000;11:31-9.
5. Badillo R, Mantilla JC, Pradilla G. Encefalitis rábica humana por mordedura de murciélago en un área urbana de Colombia. Biomedica. 2009;29(3):191-203.

6. Schneider MC, Romijn PC, Uieda W, Tamayo $\mathrm{H}$, da Silva DF, Belotto A, et al. Rabies transmitted by vampire bats to humans: an emerg- 
ing zoonotic disease in Latin America? Rev Panam Salud Publica. 2009;25(3):260-9.

7. Schneider MC, Belotto A, Adé MP, Leanes LF, Correa E, Tamayo H, et al. Epidemiologic situation of human rabies in Latin America in 2004. Epidemiol Bull. 2005;26(1):2-4.

8. Organización Panamericana de la Salud. Rabia transmitida por murciélagos hematófagos en la región amazónica: consulta de expertos. Washington, D. C.: OPS; 2006.

9. Instituto Colombiano Agropecuario. Rabia de origen silvestre en Colombia. Construcción de un modelo espacial para determinar áreas de riesgo en Colombia. Bogotá, D.C.: ICA; 2005.

10. Bortman M. Elaboración de corredores o canales endémicos mediante planillas de cálculo. Rev Panam Salud Publica. 1999;5(1):1-8.

11. Rial MJ, Alarcón N, Ferrario C, Szefner M, Califano G. Corredores endémicos: una herramienta útil para la vigilancia epidemiológica de la influenza. Rev Argent Microbiol. 2008;40:37-40.

12. Escobar Cifuentes E. La rabia transmitida por vampiros. Biomedica. 2004;24(3):1-6.

13. Organización Panamericana de la Salud. Eliminación de la rabia humana transmitida por perros en América Latina: análisis de la situación, año 2004. Washington, D.C.: OPS; 2005.

14. Oficina Internacional de Epizootias. Código Sanitario para los Animales Terrestres. Washington, D. C.: OIE; 2010.
15. Phillips SJ, Anderson RP, Schapire RE. Maximum entropy modeling of species geographic distribution. Ecol Modell. 2006;190:231-59.

16. Phillips SJ. A brief tutorial on MaxEnt. Disponible en: http://www.cs.princeton.edu/ $\% 20$ schapire/maxent/ Acceso el 23 de octubre de 2011.

17. Akbar Z, McCracken GF, Kunz TH, eds. Functional and evolutionary ecology of bats. $1 .^{\mathrm{a}} \mathrm{ed}$. New York: Oxford University Press; 2006.

18. Leyva P. El medio ambiente en Colombia. 2. a ed. Bogotá, D.C.: Instituto de Hidrología, Meteorología y Estudios Ambientales; 2001.

19. Soberón J, Townsend A. Interpretation of models of fundamental ecological niches and species' distributional areas. Biodivers Inform. 2007;2:1-10.

20. Moffett A, Strutz S, Guda N, González C, Ferro MC, Sánchez-Cordero V, et al. A global public database of disease vector and reservoir distributions. PLoS Negl Trop Dis. 2009;3:e378.

21. Hijmans RJ, Cameron SE, Parra JL, Jones PG, Jarvis A. Very high resolution interpolated climate surface for global land areas. Int J Climatol. 2005;25:1965-78.

22. Hijmans RJ, Cameron SE, Parra JL, Jones PG, Jarvis A. The WorldClim interpolated global terrestrial climate surfaces, version 1.3. Disponible en: http://biogeo.berkeley.edu/ WORLDCLIM Acceso el 22 de diciembre de 2012.

23. Urbina Cardona JN, Loyola RD. Applying niche-based models to predict endangered- hylid potential distributions: are neotropical protected areas effective enough? Trop Conserv Sci. 2008;4:417-45.

24. Vidal-García F, Serio-Silva JC. Potential distribution of Mexican primates: modelling the ecological niche with the maximum entropy algorithm. Primates. 2011;52:261-70.

25. Elith J, Phillips SJ, Hastie T, Dudik M, Chee YE, Yates CJ. A statistical explanation of MaxEnt for ecologist. Drivers Distrib. 2011;17:4357.

26. Urbina-Cardona JN, Flores-Villela O. Ecological-niche modelling and prioritization of conservation-area networks for Mexican herpetofauna. Conserv Biol. 2010;24:1031-41.

27. Hill JE, Smith JD. Bats: a natural history. Austin, TX: University of Texas Press; 1984.

28. Wimsatt WA. Transient behavior, nocturnal activity patterns, and feeding efficiency of vampire bats (Desmondus rotundus) under natural conditions. J Mammalogy. 1969;50: 233-44.

29. McNab BK. Energetics and the distribution of vampires. J Mammalogy. 1973;54:131-44.

30. Cediel N, de la Hoz F, Villamil LC, Romero J, Díaz A. The epidemiology of canine rabies in Colombia. Rev Salud Publica (Bogotá). 2010;12(3):368-79.

Manuscrito recibido el 14 de febrero de 2012. Aceptado para publicación, tras revisión, el 9 de septiembre de 2012.

ABSTRACT Objective. To update the information on the geographic distribution of battransmitted rabies foci in Colombia and evaluate the biotic and abiotic conditions associated with the incidence of this disease in the country.

Geographic distribution of wild rabies risk and evaluation of the factors associated with its incidence in Colombia, 1982-2010

Key words
Methods. Observational study of a database containing information on the wild rabies foci identified between 1982 and 2010 and the cattle population in each municipality. The municipalities were classified according to the disease's risk of transmission, and an environmental characterization of 15 variables was carried out. A maximum entropy model was developed to predict which areas had conditions appropriate for the presence of the Desmodus rotundus vector infected by the virus and to evaluate the importance of the variables employed.

Results. There were 2330 foci in 359 (31.8\%) of the country's 1128 municipalities; 144 municipalities were classified as high risk. The highest incidence rates were found in Montería, Valledupar, Riohacha, Aguachica, Unguía, Acandí, Río de Oro, Tibú, Sahagún, and San Onofre. Rabies foci were found year-round but were more frequent (linear correlation $[r]=0.64$ ) during the dry months (January to April). Temperature and precipitation were the variables contributing the greatest robustness to the prediction model.

Conclusions. Prevention and control measures should be implemented in highrisk municipalities. The best months for conducting vaccination campaigns are June, November, and December. In future analyses, biotic interaction variables should be included to improve the predictive capacity of the model.

Rabies; disease vectors; epidemiologic factors; geographical localization of risk; Colombia. 